\title{
Influência da folga financeira no Gerenciamento de Resultados nas cooperativas de crédito brasileiras
}

\author{
Ramon Rodrigues dos Santos \\ https://orcid.org/0000-0002-3413-3333 | E-mail: ramon.rodrigues@ufpe.br \\ Joséte Florencio dos Santos \\ https://orcid.org/0000-0002-5366-2548 | E-mail:jfs@ufpe.br
}

\section{Resumo}

Objetivo: Identificar a influência da folga financeira no Gerenciamento de Resultados (GR) nas cooperativas de crédito singulares brasileiras, como uma estratégia de financiamento pré-perdas.

Método: A amostra compreende 626 cooperativas de crédito singulares brasileiras no período entre 2000 e 2019 (20 anos). A variável dependente é dicotômica, buscando analisar o GR como "fato" propriamente dito, inspirada na operacionalização proposta por Dantas, Borges e Fernandes (2018). Em sequência, adicionou-se uma proxy para refletir a folga financeira das cooperativas de crédito brasileiras, baseada em indicadores de liquidez do Sistema PEARLS, o "L2". Além disso, para controle, adicionaram-se variáveis relacionadas ao perfil das operações de crédito e características da cooperativa de crédito, como o seu porte, se realizam captações de depósitos à vista, da proporção de operações vencidas (de nível B a H), spread e classificação como uma cooperativa de livre admissão de associados.

Resultados: Os resultados destacaram uma influência positiva da folga financeira no GR nas cooperativas de crédito brasileiras. Com isso, quanto maior (ou menor) a folga financeira à disposição dos gestores, maior (ou menor) a propensão à prática de GR. Logo, a folga amorteceria a interação entre incerteza e aversão ao risco, como um buffer financeiro.

Contribuições: Os resultados indicam que a "posse" da folga financeira colabora no reporte dos resultados, mitigando a percepção de risco dos cooperados e do agente regulador, intensificadas devido às características específicas e pressões econômicas, políticas e sociais exercidas pelos stakeholders.

Palavras-Chave: Folga Financeira; Gerenciamento de Resultados; Cooperativas de Crédito; Cooperativas Financeiras. 


\section{Introdução}

O cooperativismo, enquanto movimento de associação humana, tem o seu marco associado à cidade de Rochdale, distrito de Manchester, na Inglaterra (Menezes, 2018), e uma das áreas em que o avanço destas instituições se mostra mais expressivo é a do cooperativismo de crédito, ou cooperativismo financeiro, em termos mais recentes. Por meio da Lei n. ${ }^{\circ} 4.565$ (Brasil, 1964), as cooperativas de crédito foram equiparadas às demais instituições financeiras, sendo o Banco Central do Brasil (Bacen) o órgão supervisor e fiscalizador dessas instituições. No entanto, diferentemente das instituições bancárias ditas "tradicionais", o foco das cooperativas de crédito não está puramente na obtenção de resultado, mas, principalmente, no papel social que exercem (Maia \& Bressan, 2020).

Com isso, haveria um trade-off nessas relações, uma vez que, enquanto ação prática, o movimento cooperativo pode não prescindir das ideias ou doutrinas propriamente ditas, mas sim das ações conscientes dos seus gestores, com políticas traçadas de maneira precisa e fins determinados para maximizar o seu valor, a sua eficiência e a manutenção de sua posição de mercado. Mesmo sem finalidade lucrativa, devido à remuneração a partir dos produtos financeiros ofertados serem maiores do que os custos inerentes a esses produtos e às despesas para a manutenção das atividades da cooperativa, consequentemente, geramse lucros, ou no caso das cooperativas, sobras, vistas como um spread por parte da instituição para com os seus associados.

Nesse contexto, a instituição das sobras tem sido cada vez mais recorrente por parte das cooperativas de crédito, uma vez que tem sido percebida como um instrumento atrativo, tanto para com os cooperados já instituídos na organização quanto como estratégia para a captação de novos associados. Logo, ao mesmo tempo em que esse instituto é visto de maneira favorável por parte dos cooperados, empreende uma estratégia de gerenciamento por parte dos seus gestores, uma vez que esses gestores obtêm informações privilegiadas sobre o desempenho atual da cooperativa, originando, consequentemente, assimetrias informacionais e o gerenciamento de seus resultados.

A estratégia de gerenciamento para as cooperativas de crédito baseia-se na premissa de que a dispersão desses resultados é entendida pelos associados como uma medida de risco. Assim, uma menor variabilidade tende a preservar a distribuição de sobras aos associados e mitigar as percepções de risco em relação à cooperativa, uma vez que a divulgação de resultados negativos ou com uma grande variabilidade denotaria uma situação de ineficiência ou até mesmo de insegurança econômico-financeira da entidade, causando, ao extremo, desmutualizações (Maia, Bressan, Lamounier \& Braga, 2013; Silva, Niyama, Rodrigues \& Lourenço, 2018).

Esse fato é atenuado pelo fato de que as cooperativas de crédito não possuem acesso à captação de recursos pelo mercado acionário. Com isso, somada à adequação mínima de capital exigida pelos órgãos reguladores, essas instituições seriam levadas a constituir e manter uma espécie de folga financeira, a partir de recursos não aplicados pelas cooperativas singulares em operações de crédito para minimizar uma situação de excesso ou de retração do seu desempenho econômico. Com isso, este trabalho oferece um exame da capacidade de retenção de riscos da empresa, determinado pela existência de folga financeira, como função passiva (Rafailov, 2017), e não apenas como fonte ativa para investimentos ou inovação. Cabe ressaltar que no caso das cooperativas de crédito, não existem motivações pelo ponto de vista do mercado de ações, uma vez suas captações são realizadas por meio dos depósitos e/ou do capital social formado por cota-partes de seus associados. Logo, é necessário avaliar outros aspectos que possam exercer essa influência no que se refere ao gerenciamento de resultados por parte dessas instituições, como o estoque de recursos em caixa e equivalentes. 
Os dados do último relatório do Sistema Nacional de Crédito Cooperativo (SNCC), referentes ao ano de 2019, destacam que os recursos não aplicados pelas cooperativas singulares em operações de crédito são direcionados para aplicações de liquidez no mercado financeiro, diretamente pelas singulares ou por meio da aplicação centralizada de recursos, ou centralização financeira, possibilidade oferecida pelos sistemas cooperativos às suas filiadas. $\mathrm{O}$ estoque desses recursos no período supracitado estava distribuído em títulos de renda fixa, títulos e valores mobiliários vinculados, operações compromissadas e cotas de fundos de investimento, correspondendo uma participação de $33,1 \%$ dos ativos totais (Bacen, 2020a), o que permite vislumbrar a relevância desses recursos, além das atividades com as operações de crédito dessas instituições.

Nesse contexto, como o gerenciamento de resultados afeta a posição econômica da empresa, a decisão de mitigar o risco por meio do seu conjunto de caixa e equivalentes precederia a avaliação da capacidade de reter esses riscos, como um buffer financeiro, deixando-a em uma posição melhor (ou não) do que uma empresa presa em um único curso de ação. Isto posto, busca-se verificar se a folga financeira é uma motivação para que essas instituições utilizem esse mecanismo quando do gerenciamento de resultados, e sua influência, buscando levantar evidências quanto aos possíveis efeitos positivos e negativos desse buffer financeiro no desempenho das cooperativas de crédito brasileiras. A identificação dessa relação pode fornecer meios simples para que os gestores tenham meios claros para atingir os seus objetivos e para que os acadêmicos desenvolvam trabalhos que possam ir além da prática desta estratégia.

\section{Referencial Teórico}

\subsection{Os Conflitos de Agência e o Gerenciamento de Resultados (GR) em Cooperativas de Crédito}

O problema da agência tenta fornecer soluções para dois problemas fundamentais: os que surgem quando os objetivos do principal são diferentes daqueles do agente e as situações em que é difícil ou muito caro para o principal verificar as atividades do agente (Eisenhardt, 1989). Quando se postula que os gerentes do dinheiro de outras pessoas não podem protegê-lo com o mesmo zelo de quando eram seus, isso ao longo dos anos se prova correto. Todavia, a teoria da agência avança quando destaca que o relacionamento entre os atores envolvidos deve refletir uma distribuição eficiente dos custos de risco entre as partes. Cabe ressaltar, entretanto, que essa afirmação certamente ignora dois aspectos principais: o primeiro, é que os teóricos modernos das agências assumem que, após a disseminação adequada das informações e a alocação de custos com riscos, o conflito desaparece; e, em segundo, eles assumem que, em todo momento, o agente designado tem a capacidade de administrar a preocupação comercial para criar riqueza perpetuamente ou pelo menos no retorno exigido pelo principal (Kirika, 2017).

A diferença mais importante entre uma cooperativa e uma empresa comum pode estar relacionada à motivação dos membros que se comprometem com sua criação, uma vez que aqueles que se comprometem com a criação de uma empresa cooperativa buscam ser providos de bens e serviços a preço de custo. Infelizmente, este conceito, também pode vir a reduzir a sua atuação, considerando-a apenas uma função de maximização da função de utilidade de seus cooperados (Mercer, Póvoa \& Piccoli, 2019). Com isso, a primeira ideia levantada para este trabalho surge a partir da seleção adversa, uma vez que não é possível que o principal (o cooperado) verifique completamente as competências ou habilidades dos gestores enquanto estão trabalhando, ou quando, na maioria dos casos, os membros não possuem experiência comercial suficiente. Os problemas decorrentes desses conflitos são considerados um fator de risco para a sustentabilidade a longo prazo destas instituições (Menezes, 2018). 
Além disso, a dupla função das cooperativas de crédito (a de intermediário de poupança e a de "agência" de empréstimos) permite que os seus associados sejam poupadores e devedores ao mesmo tempo. Como estas instituições são de propriedade e governadas por seus membros, os seus membrosgerentes são suscetíveis a conflitos de agências entre associados (diretores) e gerentes (agentes), bem como entre membros que poupam e tomam empréstimos, o que reforça a importância de observar a dominação do grupo membro nessas entidades, uma vez que esse contexto é peculiar às cooperativas de crédito e não é observado em instituições financeiras tradicionais (Fama \& Jensen, 1983a; 1983b; Mercer, Póvoa \& Piccoli, 2019).

Para tanto, utilizando a flexibilidade de normas legais e contábeis, as cooperativas de crédito praticam o gerenciamento de resultados, com o viés de que os investidores mantenham os seus investimentos e potenciais investidores possam estar interessados em colocar o seu investimento na cooperativa ( $\mathrm{Li}$ \& Richie, 2016). Além disso, esta estratégia também refletiria o risco moral reverso da necessidade de responder a clientes "poderosos": os credores preferem proteger-se contra a possibilidade de mutuários financeiramente fracos serem levados a dificuldades financeiras; e grandes investidores com risco de concentração, devido à alta exposição à empresa, favorecem a redução da volatilidade de seus ganhos.

Nesse contexto, a instituição das sobras tem sido cada vez mais recorrente por parte das cooperativas de crédito, uma vez que tem sido percebida como um instrumento atrativo, tanto para com os cooperados já instituídos na organização, quanto como estratégia para a captação de novos associados. Caso o saldo ao final do ano seja positivo (superavitário), a distribuição das sobras não é feita em remuneração ou na medida do capital social de cada sócio, mas na razão da participação dos cooperados para a formação de tal resultado, devolvendo a cada qual a sua proporção, o que consolida nas cooperativas um princípio de justiça distributiva. Com isso, a existência de um resultado positivo ou negativo na empresa e a assimetria de informações entre as partes interessadas pode incentivar a gestão ter um comportamento disfuncional, como maximizar ou minimizar os seus resultados, buscando mostrar aos associados a sua capacidade de gerar sobras e de manter condições estáveis na cooperativa.

Os principais resultados de estudos anteriores indicam que os gestores de instituições financeiras cooperativas (que incluem as cooperativas de crédito e os bancos cooperativos) se envolveriam no gerenciamento de resultados por fatores intrínsecos à organização, como para evitar divulgar perdas (Bressan, Bressan \& Silva Júnior, 2015; Santos \& Guerra, 2018), a variação da carteira de crédito ou empréstimos vencidos (Bressan, Bressan \& Silva Júnior, 2016; Kar, 2017; Naaman, 2018) ou afetados por benchmarks externos, como o desempenho do setor, Produto Interno Bruto (PIB) ou prociclicidade dos negócios (Skala, 2015; Henselmann, Ditter \& Lupp, 2016; Olszak, Pipień \& Kowalska, 2017; Hessou \& Lai, 2018; Olszak, Roszkowska \& Kowalska, 2018; Dantas, Borges \& Fernandes, 2018; Meriläinen, 2019) e a relação com outros atributos, como a persistência das sobras (Diniz \& Girão, 2019), o conservadorismo (Santos \& Santos, 2020) ou porte da cooperativa de crédito (Diniz, 2020).

Além disso, os achados também destacaram que os reguladores do sistema financeiro dependem apenas da interpretação quantitativa das demonstrações contábeis. O lado negativo é que os desejos do principal geralmente não são levados em consideração nesta equação patrimonial; ademais, a capacidade do agente de criar riqueza para o agente não se reflete nas demonstrações financeiras, nem a sua integridade, uma vez que uma entidade pode vir a proteger contas auditadas limpas sem cometer nenhuma fraude, mas operando super ou subotimamente pelas lentes do diretor (Kirika, 2017).

Isto posto, um dos principais desafios do gerenciamento eficaz é aplicar os recursos disponíveis de uma empresa para minimizar o impacto de ameaças exógenas na organização enquanto tenta capturar as oportunidades. Além de considerar a atratividade relativa dos instrumentos financeiros disponíveis, a tomada de decisões corporativas precisa encontrar um equilíbrio entre a necessidade de adaptabilidade (futura) e o desempenho atual e futuro. Como resultado, diferentes configurações de recursos financeiros surgem e estudos empíricos descobrem que as empresas usam questões de caixa (ou equivalentes), dívida ou patrimônio disponíveis internamente de uma maneira que pode variar muito dentro de setores específicos (Gruener \& Raastad, 2018). 


\subsection{A Folga Financeira no Gerenciamento de Resultados das Cooperativas de Crédito}

A folga financeira possui várias funções-chave, como as de blindar a empresa de variações internas e externas, reduzir conflitos organizacionais por meio do fornecimento de recursos para uma ampla variedade de projetos e permitir que as empresas experimentem mudanças organizacionais e inovações, e, também, negativos, dado que a folga financeira tem sido associada, quando em níveis elevados, à ineficiência na gestão por meio de investimentos em projetos que não aumentam o valor do acionista, à falta de ambição e ao descasamento estratégico com o meio ambiente (Bradley, Wiklund\& Shepherd, 2011; Dai \& Kittilaksanawong, 2014; Silva, Rohenkohl \& Bizatto, 2018).

Além disso, a quantidade de folga financeira pode demonstrar com clareza as características da diretoria, traços e níveis de governança corporativa, além da sua gestão de riscos, o que abrange o gerenciamento de resultados (John, Li \& Pang, 2017). Sob o ponto específico das finanças, da mesma forma que o excesso de folga financeira faz com que as empresas tendam a aplicar ações estratégicas inadequadas, a sua escassez também geraria consequências negativas, uma vez que pode vir a reduzir as escolhas de decisão dos gestores, como a do gerenciamento dos resultados. Cabe ressaltar que essa prática não ocorrerá se o lucro esperado não é muito diferente do lucro real, entretanto, ao fazê-la, os gestores a administram partindo-se do pressuposto de que essa é estável em gerar lucros, o que, por consequência, faz com que a divulgação de informações de ganhos seja enganosa e causando erros na tomada de decisões por parte de que tem interesse na empresa, como seus sócios e credores (Li \& Richie, 2016).

Assim, esses recursos de folga ofereceriam, uma "margem de erro". Quando os recursos são escassos, os membros da organização gastam tempo na formação de coalizões para negociar ou justificar sua parte dos recursos limitados. Se os recursos são mais abundantes - ou seja, se existe uma folga - presume-se que a necessidade de tal postura diminua. Os pesquisadores argumentaram, portanto, que a posse de folga financeira "alivia" os conflitos, pois diferentes partes podem seguir suas próprias agendas (Gruener \& Raastad, 2018). Em ambos os possíveis resultados levantados, a "posse" da folga financeira minimizaria a percepção de risco por parte dos usuários de interesse da informação (os cooperados) e o agente regulador (o Bacen).

O entendimento restrito da folga financeira associa a folga financeira à disponível ou inabsorvida, representada pelos ativos mais líquidos e não aplicados a nenhuma atividade organizacional, de duas maneiras: índices atuais e índices rápidos. O índice atual assume a relação entre todos os ativos e passivos circulantes, enquanto o índice rápido fornece uma medida mais precisa da liquidez, removendo os estoques do ativo circulante, como o elemento menos líquido dos ativos circulantes (Dai \& Kittilaksanawong, 2014; Gruener \& Raastad, 2018; Wieczorek-Kosmala \& Błach, 2019). A liquidez também pode ser entendida como uma folga financeira de curto prazo, diferente da folga como "poder de empréstimo", classificada como uma folga financeira de longo prazo (Campos \& Nakamura, 2015).

Nesse contexto, a ideia proposta é de que a capacidade imediata de reter o risco seria determinada pela existência (ou não) de reservas de caixa vinculadas (alta participação de ativos líquidos no ativo circulante, que correspondem à folga financeira disponível. Isto posto, a folga amorteceria a interação entre a incerteza ambiental e aversão ao risco e sua ausência seria um sinal de aviso de que a empresa talvez não consiga impedir que um pequeno revés se transforme em uma ameaça séria. Tal construção demonstraria que quanto maior (ou menor) a folga financeira à disposição dos gestores, menor (ou maior) a propensão a que esses gerenciem os resultados reportados. Isto posto, segue-se a hipótese de pesquisa.

- H1: A folga financeira influencia positivamente o gerenciamento de resultados das cooperativas de crédito brasileiras. 
No caso das cooperativas de crédito brasileiras, a ideia proposta é de que, em períodos com resultados mais altos, as cooperativas de crédito tendem a aumentar suas provisões, criando discricionariamente uma espécie de reserva (econômica e não financeira) em momentos de comprometimento da performance, suavizando os seus resultados "de cima para baixo" e mantendo um maior nível de folga financeira. Em um cenário inverso, em períodos com resultados mais baixos, as cooperativas de crédito tendem a diminuir um possível gerenciamento de seus resultados por meio de provisões, criando, nesse caso, uma menor reserva financeira, mantendo, no extremo, apenas o determinado pelo órgão regulador (o Bacen).

\section{Procedimentos Metodológicos}

A amostra da pesquisa é composta por 626 (seiscentas e vinte e seis) cooperativas de crédito singulares brasileiras que dispunham de informações contábeis e não apresentaram patrimônio líquido negativo no período entre 2000 a 2019, o que correspondeu, àépoca, a 71,7\% do total de empresas em atividade (873) no ano de 2019 (Bacen, 2020b), fazendo-se, assim, um total de 12.520 observações. Dessa forma, cabem duas observações:

a. o período inicial deste projeto está relacionado à produção dos efeitos da Resolução n. ${ }^{\circ} 2.682$ (Bacen, 1999), que dispôs sobre os critérios para a classificação das operações de crédito e regras para a constituição de Provisão para Créditos de Liquidação Duvidosa (PCLD), utilizada para o cálculo da variável dependente deste trabalho;

b. foram excluídas as confederações, federações e centrais de cooperativas de crédito, partindo-se do pressuposto de que toda operação negocial com os associados está a cargo das cooperativas singulares, configurando às centrais e confederações a função de suporte operacional na prestação de serviços e o acesso aos produtos do mercado financeiro (Dantas, Borges \& Fernandes, 2018).

Os dados utilizados nesse estudo são secundários e coletados nas bases de dados disponibilizadas pelo Bacen, que consolida as informações financeiras das cooperativas de crédito brasileiras, quais sejam o "IF.Data - Dados Selecionados de Entidades Supervisionadas" (Bacen, 2020b) e os arquivos analíticos de balancetes e balanços patrimoniais (Códigos 4010 e 4016) (Bacen, 2020c), categorizados de acordo com o Plano Contábil das Instituições do Sistema Financeiro Nacional [Plano Cosif (Bacen, 1987)], denominado na presente operacionalização apenas como "Cosif". Cabe ressaltar também que os dados propostos no presente estudo já desconsideram as cooperativas em processo de incorporação, cujos dados foram consolidados nas respectivas Assembleias Gerais Extraordinárias.

A título de observação, para as informações patrimoniais das cooperativas de crédito foram utilizados os dados referentes a dezembro do respectivo período. Já para as informações de resultado, haja vista a exigência da Lei n. ${ }^{\circ} .595$ (Brasil, 1964), do encerramento dessas contas nos meses de junho e dezembro, os saldos das contas credoras e devedoras apresentados nos respectivos meses foram somados para que se tivessem os saldos totais dessas contas no respectivo ano.

Em sequência, a variável dependente proposta neste trabalho é dicotômica, denominada "GRCoop" e inspirada na operacionalização proposta por Dantas, Borges e Fernandes (2018) que utiliza a parcela discricionária das despesas com PCLD. Para se chegar a essa variável, foram realizados os seguintes procedimentos: 
a. identifica-se, a priori, o valor contábil registrado na rubrica Cosif 1.6.9.00.00-8 (Provisões para Operações de Crédito), conta retificadora do título "Operações de Crédito" (Cosif 1.6.0.00.00-1) e que representaria, em tese, os valores provisionados decorrentes da classificação das operações de empréstimos e financiamentos nos diferentes níveis de risco, conforme estabelecido na Resolução n. ${ }^{\circ} 2.682$ (Brasil, 1999). Essa primeira identificação refletiria os accruals totais da cooperativa i no período $t\left(\mathrm{PCLD}_{t, i t}\right)$;

b. em seguida, mensura-se a parcela de PCLD a partir da ponderação do valor registrado em cada rubrica contábil que reflete cada um dos níveis de risco normatizados pelo Bacen (níveis de AA a H) pelo percentual mínimo de provisão regulamentada pela Resolução n. ${ }^{\circ} 2.682$ (Brasil, 1999). Esse cálculo sensibiliza a parcela não discricionária da PCLD, ou seja, aquilo que efetivamente seria provisionado pela cooperativa i no período t considerando-se o documento supracitado. Os níveis de risco, rubricas contábeis e os respectivos percentuais são destacados na Tabela 1.

Tabela 1

Níveis de Risco e Provisão Mínima de PCLD

\begin{tabular}{cccc}
\hline Níveis de Risco & Atraso em Dias & $\begin{array}{c}\text { \% Mínimo de Provisão } \\
\text { Regulamentar }\end{array}$ & $\begin{array}{c}\text { Rubrica Contábil } \\
\text { (Conta Cosif) }\end{array}$ \\
\hline AA & - & $0,0 \%$ & $3.1 .1 .00 .00-3$ \\
\hline A & - & $0,5 \%$ & $3.1 .2 .00 .00-6$ \\
\hline B & 15 a 30 & $1,0 \%$ & $3.1 .3 .00 .00-9$ \\
\hline C & 31 a 60 & $3,0 \%$ & $3.1 .4 .00 .00-2$ \\
\hline D & 61 a 90 & $10,0 \%$ & $3.1 .5 .00 .00-5$ \\
\hline E & 91 a 120 & $30,0 \%$ & $3.1 .6 .00 .00-8$ \\
\hline F & 121 a 150 & $50,0 \%$ & $3.1 .7 .00 .00-1$ \\
\hline G & 151 a 180 & $70,0 \%$ & $3.1 .8 .00 .00-4$ \\
\hline H & acima de 180 & $100,0 \%$ & $3.1 .9 .00 .00-7$ \\
\hline
\end{tabular}

Identificada a parcela não discricionária, busca-se, então, a diferença entre os dois saldos encontrados anteriormente, quais sejam a $\mathrm{PCLD}_{i t}$ e a $\mathrm{PCLD}_{n d}$ para encontrar a parcela discricionária da PCLD, denominada PCLD ${ }_{d}$, que refletiria o excesso (ou não) no reconhecimento das perdas por critérios relacionados além do regulado pelo órgão supervisor (o Bacen), e que sensibilizariam, assim, um gerenciamento dos resultados da cooperativa i no período t. Em linhas gerais, esse saldo ( PCLD $_{d}$ ) é identificado consoante a Equação 2.

$$
\mathrm{PCLD}_{d, i t}=\mathrm{PCLD}_{t, i t}-\mathrm{PCLD}_{n d, i t}
$$

Em sequência à proposta desse trabalho, segue-se além da operacionalização proposta pelos autores, buscando um aprimoramento nesta métrica, a partir da atribuição da variável dicotômica proposta ("GRCoop"). Cabe ressaltar que a ideia de gerenciamento de resultados por parte das cooperativas de crédito tem sido operacionalizada nas instituições brasileiras em um período ainda recente, a partir de pelo menos três métricas, além da apresentada anteriormente, quais sejam: (a) por meio das despesas com PCLD, considerando-se parcelas discricionárias e nãodiscricionárias (Maia et al., 2013; Bressan, Bressan \& Silva Júnior, 2016; Bressan, Souza \& Bressan, 2017); (b) análise de frequência por histogramas (Bressan, Bressan \& Silva Júnior, 2015; Santos \& Guerra, 2018); e (c) a relação do resultado líquido das cooperativas e das receitas totais ou operacionais, para suavizar os seus resultados, por meio do Índice de Eckel (IE) (Santos \& Santos, 2020). 
Nesse sentido, em um conjunto heterogêneo, como o das cooperativas de crédito brasileiras, é característico que estudos busquem novas operacionalizações para esse fenômeno, uma vez que, além das diferenças ocasionais e intrínsecas às instituições financeiras ou não, como o porte, as legislações mais recentes relacionadas ao objeto dessa pesquisa adicionaram novas classificações às cooperativas quanto ao seu perfil de risco e às estratégias distintas de captação de recursos (Brasil, 2015, 2017). Isto posto, mensurações como a das despesas com PCLD, assim como o próprio reporte das informações financeiras, também tendem a ser influenciadas por essas segmentações que, quando analisadas em conjunto, podem apresentar problemas em questões econométricas, principalmente relacionadas à heterocedasticidade.

Com isso, propõe-se analisar o gerenciamento de resultados como "fato" propriamente dito, ou seja, considerando-se a prática ou não desse mecanismo, em vez da sua quantificação, mesmo que essa fosse ponderada pelo porte da cooperativa de crédito no respectivo período, assim como sugerido em estudos anteriores, seja pelo seu ativo total ou pelo saldo das operações de crédito que, ressalta-se, também "carregariam", nessa ponderação, o efeito de um possível gerenciamento ou não dos resultados dessas instituições.

Diante disso, a partir da identificação de parcela discricionária a partir das despesas com PCLD, propõe-se atribuir 1 (um) à variável "GRCoop". Caso contrário, ou seja, na ausência dessa parcela discricionária, atribui-se 0 (zero). Dessa forma, buscando-se uma interpretação mais objetiva desses fatos, espera-se que a variável "GRCoop" seja uma boa proxy para refletir a prática de gerenciamento de resultados nessas instituições.

Em sequência, o entendimento restrito da folga financeira a associa à folga disponível ou inabsorvida, representada pelos ativos mais líquidos e não aplicados a nenhuma atividade organizacional (WieczorekKosmala \& Błach, 2019). Assim sendo, foi adicionada ao modelo-base uma variável (ora denominada "FF") para refletir a folga financeira das cooperativas de crédito brasileiras, como uma proxy, baseada em um dos indicadores de liquidez do Sistema PEARLS, o "L2", que em linhas gerais demonstram se a instituição está gerenciando efetivamente seu caixa para atender às solicitações de retirada de depósitos e os requisitos de reserva de liquidez, conforme apresentado na Equação 3.

$$
\mathrm{L} 2=\mathrm{FF}=\frac{\begin{array}{c}
\left(\text { Cosif 1.1.0.00.00 }-6_{\mathrm{it}}+\operatorname{Cosif} 1 \cdot 2 \cdot 0 \cdot 00 \cdot 00-5_{\mathrm{it}}+\right. \\
\left.\operatorname{Cosif} 1 \cdot 3 \cdot 0 \cdot 00 \cdot 00-4_{\mathrm{it}}+1 \cdot 4 \cdot 5 \cdot 00 \cdot 00-8_{\mathrm{it}}\right)
\end{array}}{\operatorname{Cosif} 4 \cdot 1 \cdot 0 \cdot 00 \cdot 00-7_{\mathrm{it}}}
$$

- Em que: Cosif 1.1.0.00.00 - $6_{\mathrm{it}}$ : Disponibilidades; Cosif 1.2.0.00.00 - $5_{\mathrm{it}}$ : Aplicações

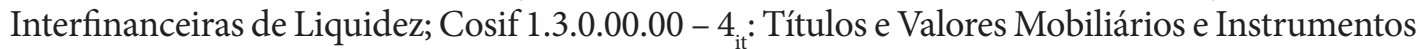
Financeiros Derivativos; 1.4.5.00.00 - $8_{\mathrm{it}}$ : Centralização Financeira - Cooperativas; e Cosif 4.1.0.00.00 - 7 it: Depósitos Totais.

A diferença para os indicadores tradicionais de liquidez para o indicador proposto está relacionada, além do que as cooperativas aplicam em títulos e valores mobiliários, às transferências de recursos das sobras de caixa para as cooperativas centrais, decorrentes do ato cooperativo denominado "centralização financeira". Com isso, o indicador considera a relação entre esses ativos de curto prazo da cooperativa de crédito não aplicados em suas operações e os seus depósitos totais (sejam à vista ou a prazo), como uma proxy para a liquidez corrente dessas instituições (Bressan, Braga, Bressan \& Resende Filho, 2010).

\footnotetext{
"PEARLS" é o acrônimo para um grupo de indicadores contábeis-financeiros derivado da avaliação das seguintes áreas-chave operacionais das cooperativas de crédito singulares: Protection (Proteção), Effective Financial Structure (Efetiva Estrutura Financeira), Assets Quality (Qualidade dos Ativos), Rates of Return and Costs (Taxas de Retorno e Custos), Liquidity (Liquidez), e Signs of Growth (sinais de crescimento). É um sistema do Conselho Mundial do Cooperativismo de Poupança e Crédito (World Council of Credit Unions - WOCCU, em inglês) que é uma agência internacional para a promoção do cooperativismo de crédito, criouo sistema PEARLS no final dos anos 80 , a partir de uma adaptação do U.S. CAMEL para o ambiente das cooperativas decrédito (Bressan, Braga, Bressan \& Rezende Filho, 2010).
} 
Para controlar o comportamento entre as métricas supracitadas, foram propostas cinco variáveis para controlar a relação proposta nesse trabalho, quais sejam: classificação como uma cooperativa "grande" ou "pequena" ("Tam"); se a cooperativa não capta depósitos à vista ("CapEmp"); proporção das operações vencidas ("OpVenc"); o spread da cooperativa ("Spread"); e, por fim, se a cooperativa de crédito permite ou não a livre admissão de associados ("LA"), cujas descrições são levantadas na Tabela 2.

Tabela 2

\section{Variáveis de Controle Propostas}

\begin{tabular}{|c|c|}
\hline Variáveis & Descrição \\
\hline 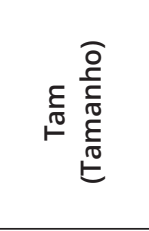 & $\begin{array}{l}\text { Buscou refletir o fato das cooperativas de crédito plenas ou com ativos totais acima dos R } \$ 50 \text { milhões } \\
\left.\text { adotarem, por exigência da Resolução n. }{ }^{\circ} 4.434 \text { (Bacen, } 2015\right) \text {, uma estrutura administrativa integrada por } \\
\text { conselho de administração e por diretoria executiva a ele subordinada, classificando-a, no escopo desse } \\
\text { trabalho, como uma cooperativa grande. Essa mesma classificação também foi aplicada nos trabalhos de } \\
\text { Diniz e Girão (2019). Isso posto, foi adicionada uma variável dicotômica, atribuindo-se } 1 \text { (um), para caso } \\
\text { enquadrada nos critérios acima mencionados no respectivo período, e } 0 \text { (zero), caso contrário. }\end{array}$ \\
\hline 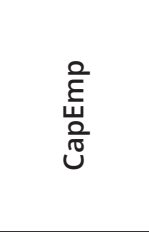 & $\begin{array}{l}\text { Indicou as cooperativas cujo funding limita-se ao capital integralizado pelos associados, sem a captação } \\
\text { de recursos ou depósitos ou transações com moeda estrangeira, a partir da classificação estabelecida } \\
\text { também pela Resolução n. }{ }^{\circ} 4.434 \text { (Bacen, 2015). A proposta é analisar se a ausência dessas captações } \\
\text { influenciaria ou não no gerenciamento de resultados dessas instituições, atribuindo-se também uma } \\
\text { variável dicotômica, sendo } 1 \text { (um), para caso a cooperativa de crédito não apresente depósitos totais no } \\
\text { período (rubrica Cosif } 4.10 .00 .00-7) \text {, e } 0 \text { (zero), caso contrário. }\end{array}$ \\
\hline 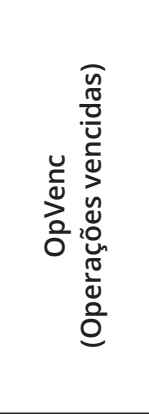 & $\begin{array}{l}\text { O Panorama do Sistema Nacional de Crédito Cooperativo (Fundo Garantidor do Cooperativismo } \\
\text { Financeiro [FGCoop], 2020) destacou que a carteira das cooperativas de crédito singulares permaneceu } \\
\text { classificada majoritariamente em níveis de risco AA, A e B ( } 71,3 \% \text { de uma carteira total de R\$ } 145.526 .063 \\
\text { bilhões). Contudo, observou-se, no período entre } 2015 \text { e } 2019 \text {, uma ligeira deterioração da classificação } \\
\text { de risco da carteira, com queda na proporção de operações em nível de risco (de } 51,5 \% \text { em } 2015 \text {, para } \\
\text { 38,9\%, em 2019), e concomitante um aumento na de níveis de risco B, C e D (somadas, de 40,4\%, em 2015, } \\
\text { para 51,4\%, em 2019), o que, por consequência, tendenciaria a um maior gerenciamento de resultados (ou } \\
\text { não). Isto posto, no presente contexto, de acordo com Bressan, Braga, Bressan \& Resende Filho, 2011), o } \\
\text { indicador "operações de crédito vencidas (a partir do nível B ao H), dividido pela carteira classificada total" } \\
\text { é relevante na determinação da probabilidade de insolvência de cooperativas de crédito brasileiras, e, no } \\
\text { interesse do presente trabalho, na determinação da influência com a variável dependente proposta. }\end{array}$ \\
\hline \multirow{3}{*}{$\frac{\overbrace{}^{2}}{3}$} & $\begin{array}{l}\text { Calculado pela diferença entre as taxas de empréstimo cobradas dos tomadores de crédito e a taxa de } \\
\text { captação paga aos clientes (Maia, Colares, Cruz \& Bressan, 2019) tem, em sua interpretação, o aspecto de } \\
\text { "quanto maior, melhor". }\end{array}$ \\
\hline & $\begin{array}{l}\text { Spread= "GerOR" - “CustoCap", em que: GerOR= (Cosif 7.1.0.00.00-8 t / Cosif 1.6.0.00.00-1 t); e CustoCap = } \\
\text { [(Cosif 8.1.0.00.00-5 - ((Cosif 8.1.8.30.30-9) + (Cosif 7.1.9.90.30-7))/(Cosif 1.6.0.00.00-1) }\end{array}$ \\
\hline & $\begin{array}{l}\text { Entretanto, essas instituições buscam um equilíbrio entre o seu desempenho econômico e social, uma vez } \\
\text { que os "lucros" para as cooperativas de crédito são, na verdade, excedentes ou "sobras" apuradas pelo } \\
\text { resultado dos produtos e serviços realizados a esses mesmos associados. Logo, o desafio da gestão se } \\
\text { torna, então, identificar quais taxas são vantajosas aos associados e suficientes para que a cooperativa } \\
\text { não comprometa sua eficiência operacional (Canassa \& Costa, 2018) e, ao mesmo tempo, fazer com que } \\
\text { esse trade-off também não comprometa os seus resultados ao final do período. }\end{array}$ \\
\hline 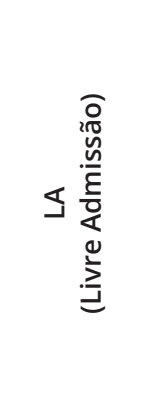 & $\begin{array}{l}\text { Em 2019, de acordo com o Panorama do Sistema Nacional de Crédito Cooperativo (Bacen, 2020a) o } \\
\text { segmento de cooperativas acentuou o processo de mudança nos critérios de associação, o que tornou } \\
\text { as singulares de livre admissão o grupo mais numeroso, contando com } 413 \text { singulares e representando } \\
\text { um aumento de aproximadamente } 10 \% \text { em relação ao período anterior. Por outro lado, as cooperativas } \\
\text { de produtor rural e as de crédito mútuo apresentaram redução de } 45 \% \text { e } 11 \% \text {, respectivamente. Com } \\
\text { isso, ano final de } 2019 \text {, as cooperativas com livre admissão de associados passaram a representar } 47 \% \\
\text { das singulares em atividade no país (40\% em dezembro de } 2018 \text { ), com participação de aproximadamente } \\
83 \% \text { do ativo total do segmento. Isto posto, a partir da importância dessas cooperativas dentro do SNCC, } \\
\text { propõe-se uma variável dicotômica, atribuindo } 1 \text { (um) para quando uma cooperativa for classificada como } \\
\text { de livre admissão e } 0 \text { (zero), caso contrário, seguindo o proposto por Maia et al. (2013), Bressan, Bressan e } \\
\text { Silva Júnior (2016) e Bressan, Souza e Bressan (2017). }\end{array}$ \\
\hline
\end{tabular}


Para a estimação do modelo, será aplicada a técnica de regressão logística binária, que é elaborada com base na estimação por máxima verossimilhança e pode ser definida por um vetor de variáveis explicativas (Fávero \& Belfiore, 2017). A partir das operacionalizações expostas, o logito ( $Z$ ) cujos parâmetros quer se estimar é definido na Equação 1.

$$
Z_{i t}=\alpha+\beta_{1} F F_{i t}+\beta_{2} T A M_{i t}+\beta_{3} \operatorname{CapEmp}_{i t}+\beta_{4} O p \operatorname{Venc}_{i t}+\beta_{5} \text { Spread }_{i t}+\beta_{6} L A_{i t}
$$

E a probabilidade estimada de que uma cooperativa de crédito realize gerenciamento de resultados por meio das despesas discricionárias com PCLD pode ser descrita da seguinte forma:

$$
\mathrm{p}_{\mathrm{i}}=\frac{1}{1+e^{-\left(\alpha+\beta_{1} F F_{i t}+\beta_{2} \text { TAM }_{i t}+\beta_{3} \operatorname{CapEmp}_{i t}+\beta_{4} \text { OpVenc }_{i t}+\beta_{5} \text { Pread }_{i t}+\beta_{6} L A_{i t}\right)}}
$$

É importante ressaltar que o logito não representa a variável dependente, denominada por Y, e sim a expressão da probabilidade $p_{i}$ de ocorrência do evento de interesse para cada observação, em função do logito $Z_{i}$, ou seja, em função dos parâmetros estimados para cada variável explicativa.

\section{Resultados}

A Tabela 3 contém as informações da estimação proposta para o presente trabalho, considerando a principal variável de interesse (FF), mensurada pelo indicador "L2" do sistema PEARLS. Os resultados apresentados indicam que a variável de interesse desse trabalho apresentou um sinal positivo e significativo ao nível de $1 \%(0,004)$, indicando que a folga financeira tem o poder de influenciar positivamente na prática do gerenciamento de resultados em cooperativas de crédito, confirmando a hipótese de pesquisa apresentada (H1). Este achado sugere que, quanto maior (ou menor) a folga financeira à disposição dos gestores, maior (ou menor) a propensão a que esses gerenciem os resultados reportados, o que demonstra que a folga financeira pode ser aplicada, dentro das cooperativas de crédito brasileiras, como uma das estratégias diretas para mitigar a percepção de risco por parte dos seus associados.

Tabela 3

\section{Resultados da Pesquisa}

\begin{tabular}{lcccc}
\hline \multicolumn{1}{c}{ Variáveis } & Coeficiente & Erro-Padrão & Estatística & $\boldsymbol{p}$-valor \\
\hline Constante & $-0,456$ & 0,041 & $-11,09$ & $0,000 * * *$ \\
\hline FF & 0,005 & 0,000 & 1,676 & $0,004 * * *$ \\
\hline Tam & 0,912 & 0,052 & 17,44 & $0,000 * * *$ \\
\hline CapEmp & $-0,659$ & 0,051 & $-12,77$ & $0,000 * * *$ \\
\hline OpVenc & $-0,157$ & 0,086 & $-1,820$ & $0,069 *$ \\
\hline Spread & 0,009 & 0,012 & 0,732 & 0,463 \\
\hline LA & 1,173 & 0,059 & 19,75 & $0,000 * * *$ \\
\hline Média var. dependente & \multicolumn{2}{c}{0,466949} & D.P. var. dependente & 0,498926 \\
\hline R-quadrado de McFadden & \multicolumn{2}{c}{0,139228} & R-quadrado ajustado & 0,138418 \\
\hline
\end{tabular}

Nota: Teste de razão de verossimilhança: Qui-quadrado (6) = 2407,15 (0,0000). Legenda: FF: Folga Financeira ("L2" do Sistema PEARLS); Tam: Tamanho da cooperativa; CapEmp: Cooperativa de Capital e Empréstimo; OpVenc: Operações vencidas; Spread: Diferença entre as taxas de empréstimo (GerOR) e captação (CustoCap); e LA: Cooperativa de Livre Admissão. D.P.: Desvio-Padrão. Significância: ***: 1\%, **: 5\% *: 10\%. 
Os defensores da folga identificam quatro funções principais, dentre as quais, de que a folga atua como um amortecedor entre as organizações e as contingências externas, o que facilita a adaptação da empresa às mudanças ambientais e, assim, melhorando o desempenho de longo prazo das empresas (Wieczorek-Kosmala \& Błach, 2019). Bradley, Shepherd e Wiklund (2011) apresentam vieses positivos, ao afirmarem que a folga financeira possui várias funções-chave, entre as quais blindar a empresa de variações internas e externas, reduzir conflitos organizacionais por meio do fornecimento de recursos para uma ampla variedade de projetos e permitir que as empresas experimentem mudanças organizacionais e inovações. No entanto, cabendo ressaltar que, em níveis mais altos de folga, o comportamento reconhecido pela teoria da agência prevalece.

A falta de clareza, em particular com relação ao papel do cooperativismo de crédito, o descompromisso com os seus direcionadores estratégicos (visão, missão e valores), a baixa dominância de seus diferenciais doutrinários e o deslumbramento com o mercado são graves ofensores à preservação da identidade cooperativa, gerando sérios riscos à desmutualização (Meinen, 2016). Com isso, a ideia de cobertura autossuficiente dos recursos financeiros das cooperativas de crédito brasileiras (aqui colocados como o conjunto de disponibilidades, equivalentes de caixa e centralização financeira) é considerada como um método de financiamento de riscos por parte dessas instituições para com os seus associados e órgãos supervisores.

Além da análise da principal variável de interesse deste estudo, testaram-se as variáveis de controle, e a respectiva relação com a prática do gerenciamento de resultados (“GRCoop"). A primeira análise, em relação à variável tamanho demonstrou que, quando uma cooperativa de crédito é classificada como "grande", conforme adotado por Diniz e Girão (2019) e Diniz (2020), maiores tendem a ser as práticas de gerenciamento de resultados por parte das cooperativas de crédito brasileiras, o que é considerado um efeito normal das operações de crédito captadas proporcionalmente por essas instituições.

Em sequência, é importante ressaltar que, especificamente nas cooperativas de crédito, não se há um incentivo específico para investimento por parte dos seus sócios. Logo, as principais fontes de capital são derivadas de quatro aspectos, em principal: dos depósitos realizados pelos sócios, sejam em contas correntes (à vista), poupança ou aplicações (a prazo); das integralizações compulsórias de cotas-parte, processo esse estabelecido pelas cooperativas no "contrato" com o associado, quando da sua admissão; das captações realizadas por meio das cooperativas centrais, quando assim subordinada; ou dos reinvestimentos originados de suas sobras.

Para Carvalho, Diaz, Bialoskorski Neto e Kalatzis (2015), as captações e aplicações, estão positivamente relacionadas à sobrevivência das cooperativas de crédito do Brasil, e a natureza (tipo) da cooperativa de crédito é relevante como fator explicativo. Com isso, no caso das instituições que não fazem as captações mediante depósitos ("CapEmp"), e que, por consequência não podem financiar-se por esses meios, tende-se, pelos achados da presente pesquisa (sinal negativo e significativo), a que essas não gerenciem seus resultados a partir de critérios discricionários e, assim, não suavizando-os em períodos de maior volatilidade.

Além disso, a prática do gerenciamento de resultados foi inversa a uma maior proporção nas operações vencidas das cooperativas de crédito brasileiras ("OpVenc"). Com isso, a perspectiva considerada é a de que uma cooperativa que possua a maior parte de suas operações de crédito em faixas de maior risco, ao estar exposta a resultados menores, são propensas a um menor gerenciamento dos seus resultados, e, outrossim, à percepção de risco por parte dos seus cooperados. Esse fato pode ser reforçado, também, pelo fato de que cooperativas de crédito smoothers seriam menos conservadoras em relação àquelas non-smoothers (que não suavizam os seus resultados) (Santos \& Santos, 2020). Cabe ressaltar que reveses podem ocorrer do fato de a cooperativa em determinado período manter o gerenciamento de seus resultados por força de ganhos extraordinários (receitas não operacionais, por exemplo, denominados de atos não cooperados) ou não necessariamente pelo componente conservador, mas pela exigência do órgão regulador em provisionar e reverter o resultado no período anterior para o período subsequente, conforme orientado pela Resolução n. ${ }^{\circ} 2.682$ (Brasil, 1999). 
Logo após, por mais que exista pouca presença de uma "agressividade" competitiva na gestão das cooperativas de crédito, o que inclui o spread adotado por essas instituições, a intensidade desta característica poderia ser positivamente relacionada ao seu desempenho. Entretanto, os achados da pesquisa não sinalizam que, ao ter um "excesso" entre a taxa de captação (por depósitos ou capital próprio) e o que foi gerado pelas receitas operacionais, haveria uma prática ou não do gerenciamento de resultados, com fins de que esse "excesso" seja maior ou menor.

Por fim, os membros das cooperativas de crédito podem desempenhar dois papéis: credores (poupadores) e devedores. Como os seus associados podem ser os dois ao mesmo tempo, os problemas de risco moral precisam ser minimizados por essas instituições (Mercer, Póvoa \& Piccoli, 2019), e o fato dessa cooperativa ser classificada como de livre admissão intensifica essas relações, devido aos interesses e prioridades de um grupo heterogêneo de associados: enquanto o primeiro quer produtos financeiros a preços competitivos, o segundo espera o maior retorno possível sobre o capital investido (Mckillop \& Wilson, 2011), e essa assimetria de informações aumenta o risco das operações dentro dessas entidades. Logo, quanto mais homogêneas forem as preocupações dos associados e, nesse escopo, quanto mais suavizada essa relação, menores seriam os custos de agência e a votação democrática expressará o desejo da maioria e não apenas de um extrato específico. Nesse contexto, tende-se a que uma cooperativa de livre admissão de associados possua a tendência a prática de um gerenciamento dos resultados.

\section{Considerações Finais}

A retenção de riscos em uma organização requer a análise de um amplo espectro de suas consequências para a manutenção do seu equilíbrio financeiro, liquidez e eficiência, e essas decisões podem ser apoiadas pela avaliação inicial da capacidade de retenção de riscos da empresa, definida nesse trabalho pela existência de folga financeira em sua função de buffer, como uma abordagem de financiamento préperdas. Com isso, a proposta do presente estudo foi analisar a influência da folga financeira na prática de gerenciamento de resultados de cooperativas de crédito brasileiras no período entre 2000 a 2019 (vinte períodos), em um total de 12.520 observações.

Para isso, a variável dependente proposta neste trabalho foi dicotômica, denominada "GRCoop" e inspirada na operacionalização proposta por Dantas, Borges e Fernandes (2018) que utiliza a parcela discricionária das despesas com PCLD, buscando-se analisar o gerenciamento de resultados como "fato" propriamente dito, ou seja, considerando-se a prática ou não desse mecanismo, em vez da sua quantificação. Em sequência, foi adicionada ao modelo-base uma variável (ora denominada "FF") para refletir a folga financeira das cooperativas de crédito brasileiras, como uma proxy, baseada em um dos indicadores de liquidez do Sistema PEARLS, o "L2", junto a outras variáveis relacionadas ao perfil das operações de crédito e características da cooperativa de crédito, como o seu porte, se realizam captações de depósitos à vista, da proporção de operações vencidas (de nível B a H), spread e classificação como uma cooperativa de livre admissão de associados.

Os resultados destacaram, diante do trade-off apresentado, uma influência positiva da folga financeira no gerenciamento de resultados nas cooperativas de crédito brasileiras, confirmando a hipótese de pesquisa levantada. Com isso, a ideia proposta é de que, em períodos de prática de gerenciamento de resultados por meio de parcelas discricionárias com PCLD, essas instituições mantêm um nível de liquidez acima do previsto. Em contraponto, na não prática do gerenciamento de seus resultados, manteriam uma liquidez estável ou abaixo do previsto, mantendo, no extremo, apenas o determinado pelo órgão regulador. A confirmação da hipótese de pesquisa refletiria um trade-off entre folga financeira, sobras ou perdas, ou seja, um discurso que poderia, entre outros aspectos, refletir o "sacrifício" da rentabilidade em nome do crescimento, e vice-versa. Isto se dá de forma específica nessas instituições, visto que, a partir das suas próprias características, à sociedade cooperativa são acrescentadas duas pressões: a política e a social, por parte dos associados e uma pressão econômica, também por parte de seus cooperados, porém, com maior intensidade por meio do órgão regulador. 
Embora a classificação da folga esteja bem estabelecida na literatura, as evidências empíricas sobre sua relevância para o desempenho financeiro, e no escopo deste trabalho, ainda não chegaram a um forte consenso. Uma razão plausível é a de que a folga financeira é uma abordagem multiteórica e que o efeito proposto pela folga na organização depende de como as diferentes teorias preveem que os gerentes usarão recursos folgados. Do ponto de vista da gestão de finanças corporativas, a atividade de uma empresa está relacionada a uma constante transformação de fundos (caixa) em ativos, pela geração de ativos fixos (investimentos) ou ativos circulantes (atividade operacional), seguida pela transformação de ativos em fundos (dinheiro). Por isso, uma outra ressalva está relacionada à cobrança de volume adequado da reserva de caixa e equivalentes, o que consome tempo, a depender da organização. Com isso, existe o risco de surgir uma perda antes que o nível de fundos necessário seja reservado. Assim, uma aplicação consciente da retenção com a folga financeira também precisaria da conjunção com outros métodos ou estratégias, até que o nível de fundos necessário possa ser contabilizado na cooperativa e salvaguardado.

Para a continuidade deste trabalho, sugere-se analisar as outras estratégias de retenção planejadas, relacionadas aos demais tipos de folga, como a remuneração ou o financiamento contingente, relacionadas às folgas recuperável e potencial, respectivamente, assim como analisar a folga disponível por outras métricas de liquidez ou de capacidade de endividamento, adaptadas para a realidade das cooperativas de crédito brasileiras.

\section{Referências}

Banco Central do Brasil [Bacen]. (1987). Circular nº 1.273, de 29 de dezembro de 1987. Instituem, para adoção obrigatória a partir do Balanço de 30.06.88, o anexo Plano Contábil das Instituições do Sistema Financeiro Nacional - COSIF. Recuperado em 11 maio, 2020 de https://www.bcb.gov.br/ pre/normativos/circ/1987/pdf/circ_1273_v1_o.pdf.

Banco Central do Brasil [Bacen]. (1999). Resolução nº 2.682, de 21 de dezembro de 1999. Dispõe sobre critérios de classificação das operações de crédito e regras para constituição de provisão para créditos de liquidação duvidosa. Recuperado em 11 maio, 2020 de https://www.bcb.gov.br/pre/ normativos/res/1999/pdf/res_2682_v2_L.pdf.

Banco Central do Brasil [Bacen]. (2015). Resolução no 4.434 de 5 de agosto de 2015. Dispõe sobre a constituição, a autorização para funcionamento, o funcionamento, as alterações estatutárias e o cancelamento de autorização para funcionamento das cooperativas de crédito e dá outras providências. Recuperado em 11 maio, 2020 de https://www.bcb.gov.br/pre/normativos/busca/ downloadNormativo.asp?arquivo=/Lists/Normativos/Attachments/48507/Res_4434_v1_O.pdf.

Banco Central do Brasil [Bacen]. (2017). Resolução no 4.557 de 23 de fevereiro de 2017. Dispõe sobre a estrutura de gerenciamento de riscos e a estrutura de gerenciamento de capital. Recuperado em 11 maio, 2020 de https://www.bcb.gov.br/pre/normativos/busca/downloadNormativo.asp?arquivo=/ Lists/Normativos/Attachments/50344/Res_4557_v1_O.pdf.

Banco Central do Brasil [Bacen]. (2020a). Panorama do Sistema Nacional de Crédito Cooperativo Data-base: dezembro/2019. Recuperado em 21 agosto, 2020 de https://www.bcb.gov.br/content/ estabilidadefinanceira/coopcredpanorama/panorama_cooperativas_sncc_2019.pdf.

Banco Central do Brasil [Bacen]. (2020b). IF.Data - Dados Selecionados de Entidades Supervisionadas. Recuperado em 12 maio, 2020 de https://www3.bcb.gov.br/ifdata/.

Banco Central do Brasil [Bacen]. (2020c). Balancetes e Balanços Patrimoniais (Transferência de arquivos). Recuperado em 12 maio, 2020 de https://www.bcb.gov.br/estabilidadefinanceira/ balancetesbalancospatrimoniais. 
Bradley, S. W., Wiklund, J., \& Shepherd, D. A. (2011). Swinging a double-edged sword: The effect of slack on entrepreneurial management and growth. Journal of Business Venturing, 26(5), pp. 537-554. Doi: https://doi.org/10.1016/j.jbusvent.2010.03.002

Brasil. (1964). Lei n. ${ }^{\circ}$ 4.595, de 31 de dezembro de 1964. Dispõe sobre a Política e as Instituições Monetárias, Bancárias e Creditícias, Cria o Conselho Monetário Nacional e dá outras providências. Recuperado em 21 agosto, 2020 de http://www.planalto.gov.br/ccivil_03/leis/14595.htm.

Bressan, V.G.F., Braga, M. J., Bressan, A.A. \& Resende Filho, M. A. (2010). Uma proposta de indicadores contábeis aplicados às cooperativas de crédito brasileiras. Revista de Contabilidade e Controladoria, 2(3) pp. 58-80.Doi: 10.5380/rcc.v2i3.19625

Bressan, V. G. F., Braga, M. J., Bressan, A. A., \& Resende Filho, M. A. (2011). Uma aplicação do sistema PEARLS às cooperativas de crédito brasileiras. Revista de Administração, 46(3), pp. 258-274. DOI: $10.5700 /$ rausp 1011

Bressan, V. G. F., Bressan, A. A., \& Silva Júnior, J. M. da (2015). Evitar Divulgar Perdas: Foi Uma Estratégia Utilizada na Última Década pelas Cooperativas de Crédito Filiadas ao Sicredi?. Revista de Gestão e Organizações Cooperativas, 2(3), pp. 27-42. Recuperado em: https://periodicos.ufsm.br/rgc/article/ view/16336/pdfBressan, V. G. F., Bressan, A. A., \& Silva Junior, J. M. da (2016). Gerenciamento de resultados em cooperativas no Brasil: Avaliando o Income Smoothing às filiadas do Sicredi. Advances in Scientific and Applied Accounting, 9(3), pp. 283-300. Recuperado em: https://asaa.anpcont.org. br/index.php/asaa/article/viewFile/204/166

Bressan, V. G. F., Souza, D. C. D., \& Bressan, A. A. (2017). Income smoothing: a study of the health sector's credit unions. Revista Brasileira de Gestão de Negócios, 19(66), pp. 627-643.Doi: 10.7819/rbgn. v0i0.2617

Campos, A. L. S., \& Nakamura, W. T. (2015). Rebalanceamento da estrutura de capital: endividamento setorial e folga financeira. Revista de Administração Contemporânea, 19 (SPE), pp. 20-37. Recuperado em: https://www.redalyc.org/articulo.oa?id=84039480008

Canassa, B. J., \& Costa, D. R. de M. (2018). Ciclo de vida das cooperativas de crédito brasileiras: o desempenho da cooperativa como motivo para a descontinuidade das operações. Revista de Gestão e Organizações Cooperativas, pp. 51-68. Doi: https://doi.org/10.5902/2359043230202

Carvalho, F. L., Diaz, M. D. M., Bialoskorski Neto, S., \& Kalatzis, A. E. G. (2015). Saída e insucesso das cooperativas de crédito no Brasil: uma análise do risco. Revista Contabilidade \& Finanças-USP, 26(67), pp. 70-84. Doi: https://doi.org/10.1590/rcf.v26i67.98099

Dai, W., \& Kittilaksanawong, W. (2014). How are different slack resources translated into firm growth? Evidence from China. International Business Research, 7(2), pp. 1-12. Doi: 10.5539/ibr.v7n2p1

Dantas, J. A., Borges, M. A. B., \& Fernandes, B. V. R. (2018). Gerenciamento de resultados contábeis em cooperativas de crédito no brasil. Revista Ambiente Contábil, 10(2), pp. 342-363.Doi:https://doi. org/10.21680/2176-9036.2018v10n2ID14112

Diniz, M. M. \& Girão, L. F. de A. P. (2019, julho). Persistência das Sobras: Uma análise nas Cooperativas de Crédito singulares brasileiras. Anais do USP International Conference in Accounting, São Paulo, SP, Brasil, 19. Recuperado em 11 maio, 2020 de https://congressousp.fipecafi.org/anais/Anais2019_ NEW/ArtigosDownload/1690.pdf.

Diniz, M. M. (2020). Qualidade da Informação Contábil: Um estudo das Cooperativas de Crédito Brasileiras (Dissertação (Mestrado). Programa de Pós-Graduação em Ciências Contábeis, Universidade Federal da Paraíba, João Pessoa, PB, Brasil. Recuperado em 11 maio, 2020 de http:// www.ccsa.ufpb.br/ppgcc/contents/documentos/dissertacoes/dissertacao-marcelo-maia-dinizdeposito.pdf/view. 
Eisenhardt, K. M. (1989). Agency theory: An assessment and review. Academy of Management Review, 14(1), pp. 57-74. Doi: https://doi.org/10.2307/258191

Fama, E. F., \& Jensen, M. C. (1983a). Agency problems and residual claims. The Journal of Law and Economics, 26(2), pp. 327-349. Recuperado em: https://www.jstor.org/stable/725105

Fama, E. F., \& Jensen, M. C. (1983b). Separation of ownership and control. The Journal of Law and Economics, 26(2), pp. 301-325. Recuperado em: https://www.jstor.org/stable/725104

Fávero, F., \& Belfiore, P. (Ed.) (2017). Manual de Análise de Dados: Estatística e Modelagem Multivariada com Excel $^{\oplus}$, SPSS ${ }^{\bullet}$ e Stata ${ }^{\oplus}$. Rio de Janeiro: Elsevier.

Fundo Garantidor do Cooperativismo Financeiro [FGCoop]. (2020). Relatório do Sistema Nacional de Crédito Cooperativo - SNCC 2019. Recuperado em 11 maio, 2020 de https://www.fgcoop. coop.br/api/Content/Getfile?fileRef=/site-externo/Lists/normaspublicacoes/Attachments/196/ Relat\%C3\%B3rio\%20Anual\%202019.pdf.

Gruener, A., \& Raastad, I. (2018). Financial Slack and Firm Performance During Economic Downturn. Journal of Business Management and Administrative Affairs, 1(1), pp. 1-16. Recuperado em: http:// gslpublishers.org/journals/view-issue.php?title=financial-slack-and-firm-performance-duringeconomic-downturn

Henselmann, K., Ditter, D., \& Lupp, P. (2016). The Effects of the Financial Crisis on Cooperative Banks in Europe - A Critical Comparison - No. 2016-1. Working Papers in Accounting Valuation Auditing. Recuperado em 11 maio, 2020 de https://www.econstor.eu/handle/10419/161671.

Hessou, H., \& Lai, V. S. (2018). Basel III capital buffers and Canadian credit unions lending: Impact of the credit cycle and the business cycle. International Review of Financial Analysis, 57, pp. 23-39. Doi: https://doi.org/10.1016/j.irfa.2018.01.009

Jensen, M. C. (1986). Agency costs of free cash flow, corporate finance, and takeovers. The American Economic Review, 76 (2), pp.323-329. Recuperado em: https://www.jstor.org/stable/1818789

John, K., Li, Y., \& Pang, J. (2017). Does corporate governance matter more for high financial slack firms?. Management Science, 63(6), pp. 1872-1891. Doi: 10.1287/mnsc.2015.2392

Kar, A. K. (2017). Income smoothing, capital management and provisioning behaviour of microfinance institutions: A study using global panel data. The European Journal of Development Research, 29(1), pp. 108-126. Doi: 10.1057/ejdr.2015.81

Kirika, S. K. (2017). By-product Extraction of a Rationality-based Agency Conflict Index from Selected Credit Unions in Kenya: Introducing the Agency Conflict Discriminant. Journal of Business and Financial Affairs, 6(3), pp.1-6. Doi: 10.4172/2167-0234.1000279

Li, S., \& Richie, N. (2016). Income smoothing and the cost of debt. China Journal of Accounting Research, 9(3), pp. 175-190. Doi: https://doi.org/10.1016/j.cjar.2016.03.001

Maia, S. C., Bressan, V. G. F., Lamounier, W. M., \& Braga, M. J. (2013). Gerenciamento de resultados em cooperativas de crédito no Brasil. Brazilian Business Review, 10(4), pp. 96 - 116. Recuperado em: http://hdl.handle.net/1843/BUOS-98DH2H

Maia, L. L.; Colares, A. C. V.; Cruz, N. G. da \& Bressan, V. G. F. (2019). Fatores Influenciadores da Rentabilidade das Cooperativas de Crédito Brasileiras. Anais do Congresso da Associação Nacional de Programas de Pós-Graduação em Ciências Contábeis, São Paulo, SP, Brasil, 13. Recuperado em 11 maio, 2020 de http://www.anpcont.org.br/pdf/2019_CUE206.pdf.

Maia, L. L. \& Bressan, V. G. F. (2020). Política de distribuição de sobras em cooperativas de crédito. Revista de Gestão e Organizações Cooperativas, 7, pp. 157-174.Doi:10.29327/ebpc.169941 
McKillop, D., \& Wilson, J. O. (2011). Credit unions: A theoretical and empirical overview. Financial Markets, Institutionse Instruments, 20(3), pp. 79-123.Doi: 10.2139/ssrn.1702782

Meinen, E. (2016). Cooperativismo Financeiro: Virtudes e Oportunidades. Brasília: Editora Confebras.

Menezes, A. (2018). Os dois pinheirinhos continuam firmes? Educação Cooperativista. Brasília: Editora Confebras.

Mercer, A. C., Póvoa, A., \& Piccoli, P. (2019). Credit Union Member Group Domination Under High Interest Rate Environments. Annals of Public and Cooperative Economics, 90(3), pp.555-571. Doi: https://doi.org/10.1111/apce.12228

Meriläinen, J. M. (2019). Western European Stakeholder Banks' Loan Loss Accounting. Journal of Financial Services Research, 56(2), pp. 185-207.

Naaman, C. (2018). Three Essays on Credit Unions. Tese (Doctor of Philosophy, Business Administration). Concordia University. Montreal, Quebec, Canadá. Recuperado em 11 maio, 2020 de https:// spectrum.library.concordia.ca/984763/1/Naaman_PhD_S2019.pdf.

Olszak, M., Pipień, M., Kowalska, I., \& Roszkowska, S. (2017). What drives heterogeneity of cyclicality of loan-loss provisions in the EU?.Journal of Financial Services Research, 51(1), pp. 55-96. Doi: 10.1007/s10693-015-0238-6

Olszak, M., Roszkowska, S., \& Kowalska, I. (2018). Macroprudential policy instruments and procyclicality of loan-loss provisions-cross-country evidence. Journal of International Financial Markets, Institutions and Money, 54, pp. 228-257. Doi: 10.1016/j.intfin.2018.01.001

Rafailov, D. (2017). Financial Slack and Performance of Bulgarian Firms. Journal of Finance and Bank Management, 5 (2), pp. 1-13. Doi: 10.15640/jfbm.v5n2a1

Santos, L. \& Guerra, C. (2018). Gerenciamento de resultados e eficiência: um estudo nas cooperativas de crédito filiadas ao sistema Unicred. Revista de Gestão e Organizações Cooperativas, 5 (10), pp. 19 32. Doi: $10.5902 / 2359043228940$

Santos, R. R. dos, \& Santos, J. F. dos. (2020). Income smoothing practices and conservatism in Brazilian credit unions. Revista Pensamento Contemporâneo em Administração, 14(1), pp. 76-88. Doi: https:// doi.org/10.12712/rpca.v14i1.38886

Silva, C. A. M., Niyama, J. K., Rodrigues, J. M., \& Lourenço, I. C. (2018). Gerenciamento de resultados por meio da perda estimada de créditos em bancos brasileiros e luso-espanhóis. Revista Contemporânea de Contabilidade, 15(37), pp. 139-157. Doi: 10.5007/2175-8069.2018v15n37p139

Silva, T. P. da, Rohenkohl, L. B. \& Bizatto, L. S. (2018). Relation between Financial Slack and Economic Performance in Companies above and below 50 Years Old. Cuadernos de Contabilidad, v. 19 (47), pp. 130-148.Doi: https://doi.org/10.11144/Javeriana.cc19-47.ffde

Skała, D. (2015). Saving on a rainy day? Income smoothing and procyclicality of loan-loss provisions in central European banks. International Finance, 18(1), pp. 25-46. Doi: 10.1111/1468-2362.12058

Wieczorek-Kosmala, M. \& Błach, J. (2019). Financial Slack and Company's Risk Retention Capacity. In P. Linsley, P. Shrives, \& M. Wieczorek-Kosmala, (Eds.). Multiple Perspectives in Risk and Risk Management, pp. 145-168. Cham, Suíça: Springer. Doi: 10.1007/978-3-030-16045-6_6 